\title{
MOLECULAR DOCKING AND QUANTITATIVE STRUCTURE- ACTIVITY RELATIONSHIP (QSAR) STUDIES OF SOME SELECTED ANTI-ULCER INHIBITORS
}

\author{
M.B Muhammad ${ }^{*}$, A Uzairu' ${ }^{1}$, G.A. Shallangwa ${ }^{1}$, S. Uba ${ }^{1}$ \\ ${ }^{1}$ Ahmadu Bello University, Department of Chemistry P.M.B. 1044, Zaria, Kaduna State Nigeria \\ ${ }^{*}$ Corresponding author. Ahmadu Bello University, Department of Chemistry, Zaria, Kaduna, Nigeria, Phone: +2348063659427. \\ e-mail address: mmbaba247@gmail.com.
}

\begin{tabular}{l} 
A R T I C L E I N F O \\
\hline Article history: \\
Received 2018-04-25 \\
Accepted 2018-06-11 \\
Available online 2019-03-08 \\
$k$ e ywords \\
$\mathrm{K}^{+} / \mathrm{H}^{+}$AT-pase \\
Quantitative structure-activity \\
relationship \\
Genetic function algorithm \\
Peptic ulcer diseases \\
Density functional theory \\
(B3LYP/6-31G*)
\end{tabular}

\begin{abstract}
A B S T R A C T
Proton pump inhibitors portray the first choice for treating various ulcer disease, because they inhibis $H^{+} / K^{+}$-ATpase enzyme by covalently binding to a cysteine residue of either potassium or proton pump. Therefore, this enzyme is a validated target for anti-ulcer remedy/drugs. A quantitative structure-activity relationship and molecular docking studies have been made on 30 benzo[d]thiazole series as $H^{+} / K^{+}$-ATPase inhibitors. Density Functional Theory was used to optimize the geometry of the anti-ulcer compounds. Four types of molecular descriptors were generated in other to know the relationship that exit between anti-ulcer activity and structural properties of these compounds. The QSAR result revealed high statistically significant correlation coefficients $R^{2}=0.9401, R^{2} a d j=0.9250, Q^{2}{ }_{\text {LOO }}=$ 0.8842 and $R^{2}$ pred $=0.7975$. Our QSAR model showed an excellent predictive activity with the chemical properties of the compounds. The results of the docking analysis revealed that most of the compounds showed a very good relationship with the active receptor, with a better docking score of $-9.1 \mathrm{kcal} / \mathrm{mol}$. The physicochemical parameters are to be considered when improving the inhibitory activities of benzo[d] thiazole against the enzyme that causes the ulcer $\left(H^{+} / K^{+}\right.$-ATPase $)$.
\end{abstract}




\section{INTRODUCTION}

An ulcer can be referred to as an area in the digestive system where the tissue has been damaged or destroyed by stomach juice or other digestive enzymes (Chaudary et al., 2015). Peptic ulcer disease is the "umbrella term" used to describe all gastrointestinal tract disorders (ulcers). Other various types of ulcer include acute and chronic ulcer (Rakesh et al., 2017), and can be ascribed to imbalances between aggressive factors such as acid and pepsin, and protective factors such as bicarbonates, blood flow and mucous membrane, in the stomach. This balance may be disturbed due to Helicobacter pyroli infection (Skoglung, 2008; Rakesh et al., 2017; Wang et al., 2017), a gram-negative bacteria parasite, which has successfully colonized more than half of human population, and caused about $15-20 \%$ of pathologies such as adenocarcinomas, duodenal ulcer, and stomach lymphomas (Shi et al., 2016). Pain-killer drugs, such as ibuprofen, naproxen and diclofenac, which contain carboxylic groups are also believed to cause about $40 \%$ of peptic ulcer diseases (Fashner and Gitu, 2015; Shamsudeen et al., 2009). $\mathrm{H}^{+} / \mathrm{K}^{+}$-ATPase is a member of the class $2 \mathrm{C}$ P-type ion-transport ATPases. Also known as the primary gastric proton pump, which moves acid across parietal cells, and gastric mucosa (Rakesh et al., 2017). It was reported that $\mathrm{H}^{+} / \mathrm{K}^{+}$-ATPase (gastric proton/potassium pump) is the last passage of gastric acid secretion, and hypersecretion of this acid result in severe superior gastrointestinal bleeding (Wang et al., 2017). Common symptoms of the diseases include episodic gnawing, abdominal pain, vomiting and loss of appetite (Shamsudeen et al., 2009). The pain is typically alleviated when the stomach is empty, 2 to 5 hours after meals (Skoglung., 2008).

Peptic ulcer disease is one of the life-threatening diseases, that affect the large population of the world (Skoglung, 2008). Approximately 500,000 people are affected by the diseases in the United States, new 4million cases of peptic ulcer complications, $1.8 \%$ lifetime prevalence $(8-14 \%)$ with annual costs of $\$ 4.82$ billion in the developing countries (Noor et al., 2017). Men are more vulnerable to peptic ulcer diseases compared to women, and this is due to their engagement in alcohol drinking, and cigarette smoking in the society (Rajesh $e t$ al., 2016). The widespread use of the antibiotic such as amoxicillin, clarithromycin, lansoprazole and omeprazole at present, is hardly effective due to increasing resistance of the bacterium to the classes of these drugs (Drini, 2017). Excess use of pain-killer drugs can cause mucosal injury, inflammation, intestinal permeability, protein loss, with a severe complication like anemia, obstruction diverticulum, ileal dysfunction and diaphgram structures (Utzeri \& Usai, 2017). Therefore, in other to narrow the aforementioned problems, demand in search and design of novel compounds possessing anti-ulcer, and inflammation action with an improved profile is still a necessity (Rakesh et al., 2017; Mabeka, 2017).

Anti-ulcer drugs exert their action by blocking the $\mathrm{H}^{+} / \mathrm{K}^{+}$-ATPase enzyme, which is the final step of gastric acid secretion in the stomach (Anan and Wakode, 2017). H. pylori secrete CagA, (Cytotoxin-associated gene A), which is a poisonous substance produced by the bacterium after translocation into host cell, it alters cell shape, increase cell motility, redirect cell junction activity and thus responsible for gastric carcinomas and gastric ulcer (Kaur, et al., 2012; Lanas, 2017). Therefore, the bacteria is also considered as a validated target for antiulcer agents. Benzo[d]thiazoles are bicyclic ring systems that are widespread and abundant in natural products
(Wang et al., 2017). Today heterocyclic compounds, have attracted many attention of medicinal chemist. Which is attributed their diverse biological activities such as antimalarial, anti-inflammatory, antimicrobial, anticonvulsant, antioxidant, and antidiabetic activities (Rajesh et al., 2017; Ya-Li et al., 2015). Hydrazone Schiff bases are family of compounds that contain an azomethine group $(-\mathrm{CH}=\mathrm{N}-)$ in their structure. Different derivatives of benzothiazole substituted at the 2 position have diverse therapeutic applications and anticancer effects.

Computational design of novel molecule is a method that has been applied to speed drug discovery process, resulting in its acknowledgment and popularity. More also it inclination to reduce the classical trial and error approach (David et al., 2018). QSAR and molecular docking method are widely used to discover the novel blow for various therapeutic targets, and also help medicinal chemists to identify essential features associated to biological activities of molecules. (Pawar et al., 2014). QSAR studies also play a crucial role as predictive tools for a molecular development, and this is due to their low cost, little time involve in examining a large number of compounds (Castillo-Garit et al. 2012). Molecular docking show how two or more molecular structures interact with each other for example, determination of how a chemical substance and receptor are lock together in a model. This place demands on the use of the computational method, which must be quick and suitable (Abdulfatai et al., 2017). The main aim of this work is to search for effective antiulcer inhibitors (Shi et al., 2016), using QSAR and molecular docking studies.

\section{MATERIAL AND METHOD}

\section{Experimental dataset collection}

30 series of benzo[d]thiazole derivatives, identified from literature experimentally proven to inhibit $\mathrm{H}^{+} / \mathrm{K}^{+}$-ATPase were used for this study (Wang et al., 2017). the inhibitory activities of these compounds measured as $\mathrm{IC}_{50}(\mu \mathrm{M})$ were normalized and expressed in logarithmic scale as $\mathrm{pIC}_{50}\left(\mathrm{pIC}_{50}=\log 1 / \mathrm{IC}_{50}\right) \cdot \mathrm{pIC}_{50}$ was chosen as a reliable/dependent variable, which was correlated with the independent variable descriptors. Using Genetic function algorithm. The chemical structures and the $\mathrm{PIC}_{50}$ (anti-ulcer activities), of these compounds are shown in Table 1.

\subsection{Dataset division}

The biological data set was divided into a training and test set, in such a way that $70 \%$ (21) of the data set was made up of the training set while $30 \%$ (9) of the biological data was used as the validation test. Kennard-Stone Algorithm was used for the division of the biological data into a training set and validation/test set (Kennard and Stone, 1969).

\subsection{Calculation of molecular descriptors}

The Padel descriptor software version 2.18 was used for the generation of the $1 D, 2 D$ and $3 D$ descriptors from the optimized structures of the Spartan files saved as sdf file format which is the recommended input file format for the Padel descriptor software (Yap 2011). 


\subsection{Model Building}

The model was build using material studio software at Genetic Function Algorithms (GFA). The generated chemical descriptors from Padel software tool were submitted for regression analysis with the $\mathrm{PIC}_{50}$ values chosen as the relying variable, while the descriptors were selected as unrelying variables. The regression equation was 4 which represent the number of the descriptors, 1000 was chosen for the Population, and 500 was input for the Generation parameter. The mutation probability was 0.1 , and the top equation number was 4 , smoothing parameter is 0.5. Friedman's Lack of Fit (LOF) was used to score the model and other statistical parameters such as correlation coefficient matrix $\left(\mathrm{R}^{2}\right)$ for the internal, and $\mathrm{R}^{2}$ prd for external validation, statistical significance was determined using $\mathrm{F}$ test (Fischer's value); $\mathrm{Q}^{2}$ (cross-validated correlation coefficient). 'Equation 1 shows the Friedman's lack of fit formula.

$L O F=\operatorname{SSE} /\left(1-\frac{C+d p}{M}\right)$

SSE is the sum of square of errors, $c$ refers to the number of terms in the model, other than constant time, $p$ is the total number of descriptors, while $\mathrm{d}$ is a user-defined smoothing parameter. $\mathrm{P}$ is the total number of descriptors contained in all model terms, and $\mathrm{M}$ is the number of samples in the training set. Equation 2 show's structure of the regression model formula (David et al., 2018).

$Y=a_{1} x_{1}+a_{2} x_{2}+a_{3} x_{3}+b$

$\mathrm{Y}$ is the activity $\left(\mathrm{pIC}_{50}\right)$, where 'a's and ' $\mathrm{x}$ 's are regression coefficients for a conforming Nonpartisan variable representing molecular descriptors of the molecules, the 'a's correspond to ' $x$ 's. While the last variable ' $c$ ' is the regression constant.

\subsection{Geometry optimization}

ChemDraw Ultra 12.0 software was used to sketch chemical (2D) structure of the molecules, and were saved as cdx file format. The structures were then converted to 3D using Spartan 14.0 version 1.1.2 software. The calculation was carried out using molecular mechanics force field (MM $\mathrm{n}+$ ), to minimize the energy of the molecules prior to the quantum chemical calculations.

6-311G* basis set, of density functional theory (DFT) using the B3LYP method was used for whole geometry optimization of the structures to obtain the lowest energy for all the compounds in this study (Abdulfatai et al., 2017). The DFT method uses Becke's three-parameter functional (B3) with gradient correlation functional of Lee, Yang and Parr (LYP) which integrates a mixture of HF with DFT exchange terms.

\subsection{Quality assurance of the model}

The QSAR model exploits in this study, was evaluated through the use of internal and external validations parameters. The reliability and fatal capability of the model can also be determined using the parameter.

\subsection{Validation of the model}

The standard used to compare internal and external validation parameters of a particular QSAR model is shown in table 2 (Abdulfatai et al., 2017). Component of the total variation assign to the model is known through the square of the correlation coefficient $\left(\mathrm{R}^{2}\right)$ parameter. $\mathrm{R}^{2}$ is commonly used for internal validations, and the closer the $R^{2}$ to 0.1 the better the regression equation tell us more about $\mathrm{Y}$ variable. The expression for $\mathrm{R}^{2}$ is given below:

$R^{2}=1-\frac{\Sigma\left(Y_{\text {obs }}-Y_{\text {pred }}\right)^{2}}{\sum\left(Y_{\text {obs }}-\bar{y}_{\text {training }}\right)^{2}}$

where $\mathrm{Y}_{\text {pred }}, \mathrm{Y}_{\mathrm{obs}}$ and $\mathrm{Y}_{\text {mntraining }}$ are the predicted activity, the second is the experimental activity, while the latter represents the mean experimental activity of the sample in the training set compounds (Abdulfatai et al., 2017).

Adjusted $R^{2}\left(R^{2}\right.$ adj) value varies directly with the increase in the number of repressors i.e. descriptors. 'Equation 4 shows the adjusted $\mathrm{R}^{2}$ formula.

$R^{2}$ adj $=1-\left(1-R^{2}\right) \frac{n-1}{n-p-1}=\frac{(n-1) R 2-p}{n-p+1}$

The letter $\mathrm{n}$ is the number of training set compounds, $\mathrm{p}$ is the number of independent variables in the model (Brand and Orr 2015). Equation 5 shows the formula for leave one out cross validation coefficient $\left(\mathrm{Q}^{2}\right)$.

$Q^{2}=1-\frac{\Sigma(Y p-Y)^{2}}{\Sigma(Y-Y m)^{2}}$

where Yp explain predicted activity, and Y represent observed activity of the training set, and Ymntrng is the average activity value of the training set (Abdulfatai et al., 2017; Jalali-Heravi and Kyani, 2004).

\subsection{Applicability domain}

A QSAR model is an essential statistical tool used to determine whether a model make a good prediction within its applicability domain, and this can be determined from Williams plot (Tropsha et al., 2003). There are some techniques for assessing the suitable space of a QSAR model, Leverage is one of them and is given for a chemical compound as $h_{i}$ : 'Equation 6 shows leverage formula.

$$
h i=X_{i}^{T}\left(X^{T} X\right)^{-1} X^{i}
$$

The $x_{i}$ represents the row-vector of the compounds' $\mathrm{X}$ is the number of times constant descriptors matrix of the training set compound. It's used as the prediction tool of the warning leverages $\left(h^{*}\right)$ emulating the limit for $\mathrm{X}$ values. Thus $\left(h^{*}\right)$ is shown in equation 7 below.

$$
h^{*}=\frac{3(P+1)}{N}
$$


Table 1- Shows the structures and the activity $\left(\mathrm{pIC}_{50}\right)$ of the benzo[d]thiazole derivatives.

\section{S/NO}

$\mathrm{pIC}_{50}$

$\mathrm{S} / \mathrm{NO}$

Molecular structure

$\mathrm{pIC}_{50}$

$1 \mathrm{a}$

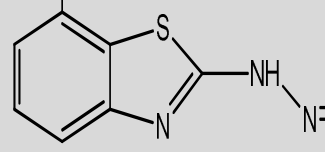

$2 b$<smiles>Cc1cccc2ncsc12</smiles><smiles>CCC(=NC)N/N=C\c1ccc([N+](=O)[O-])cc1</smiles>

$4 \mathrm{a}$

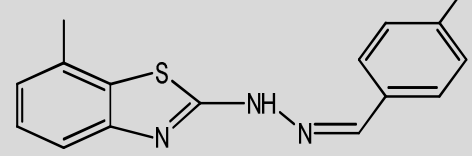

$5 b$<smiles>Cc1cccc2nc(N/N=C\c3ccc(Br)cc3)sc12</smiles>

$6 \mathrm{a}$

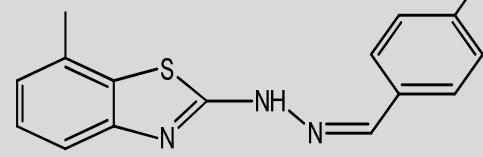

$7 a$<smiles>Cc1cccc2nc(N/N=C\c3ccccc3)sc12</smiles>

$$
{ }_{N}-\mathrm{H}_{\mathrm{N}}
$$

$9 a$

$$
\overbrace{\mathrm{N}}^{\mathrm{S}}-\mathrm{H}_{\mathrm{N}}^{\mathrm{I}}
$$

$10 \mathrm{a}$

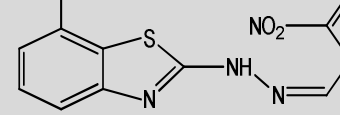

$11 b$<smiles>Cc1cccc(/C=C(\S)N/N=C\c2ccc(F)cc2F)c1</smiles>

$23 a$<smiles>Cc1cccc2nc(N/N=C/c3ccncc3)sc12</smiles>

$$
{ }_{N}-{ }_{N}^{B-}
$$

$14 b$

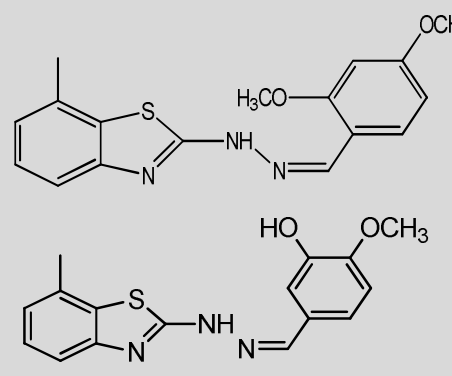

4.57
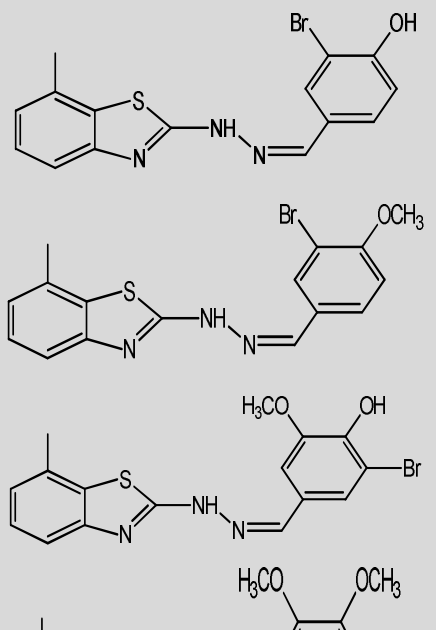

4.51

$$
\text { - }
$$

4.17

$21 \mathrm{a}$

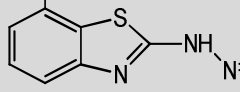

4.17

$22 \mathrm{a}$

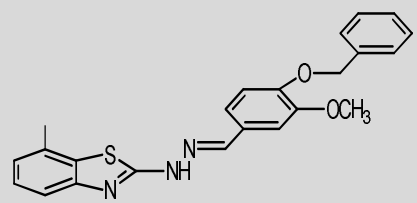

4.16

$27 a$

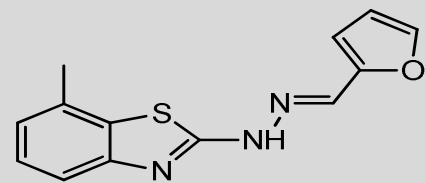




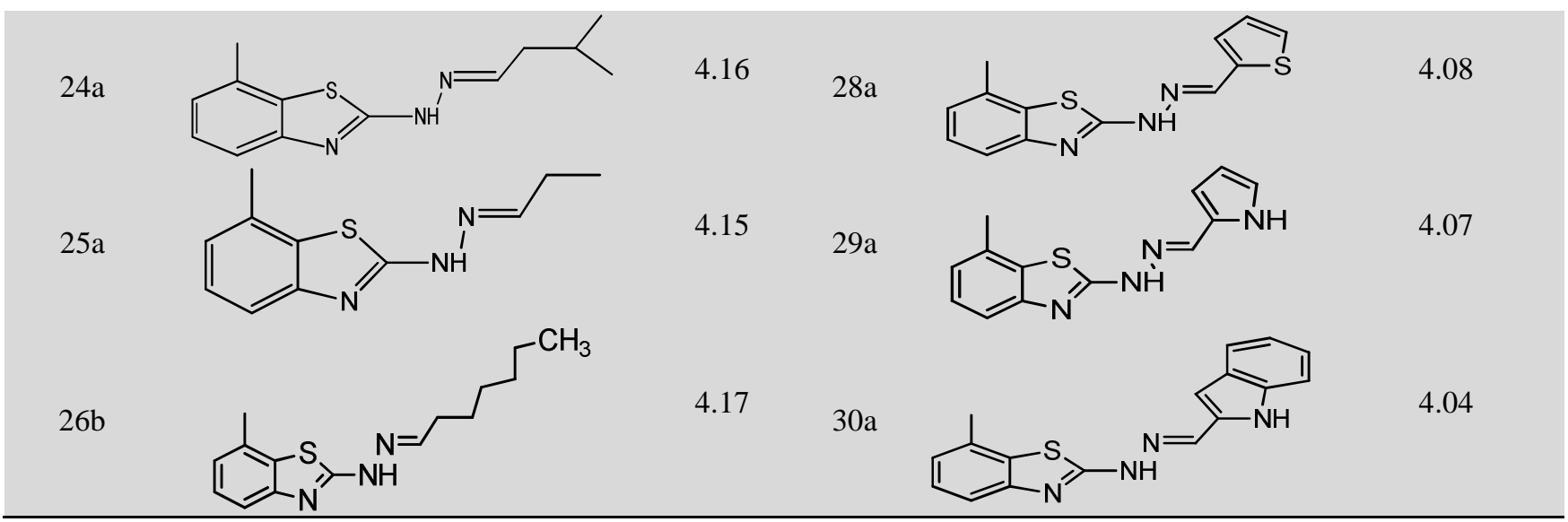

The letter ' $a$ 'is the training set, while ' $b$ ' represents test set. The small letter is the number of training set compounds, while $p$ is the number of descriptors that will be used to generate the model. Williams plot is the plot of standardized residual against the leverages, which give information on the pertinent surface of the model in terms of chemical range. The compounds that lie outside the chemical domain (standardized residual no greater than 3 standard deviation units) are known as $\mathrm{Y}$ influential, while any compound that is above the chemical domain are called outliers.

Table 2-Show's the general lowest acceptable value for the evaluation of the quantitative QSAR model.

$\begin{array}{lll}\text { Name } & \text { Symbols } & \text { Value } \\ \mathrm{R}^{2} & \text { Coefficient of determination } & \geq 0.5 \\ \mathrm{P}(95 \%) & \text { Confidence interval at 95\% } & <0.05 \\ & \text { confidence level } & \\ \mathrm{Q}^{2} & \text { Cross-validation coefficient } \geq 0.5 \\ \mathrm{R}^{2}-\mathrm{Q}^{2} & \text { Difference between } \mathrm{R} 2 \text { and } & \leq 0.3 \\ & \text { Q2 } & \\ \mathrm{N}_{\text {ext. Test }} & \text { Minimum number of } \geq 5 \\ \text { set } & \text { external test set } \\ \mathrm{R}^{2} \text { ext } & \text { Coefficient of determination } \geq 0.5 \\ & \text { for external test set }\end{array}$

\subsection{Molecular Docking studies}

Docking of protein-ligand of some benzo[d]thiazole derivatives was evaluated in other to investigate the interaction between the active site of $\mathrm{H}^{+} / \mathrm{K}^{+}$-ATPase enzyme and the ligands and this was based on the internal validation statistical parameters of the model as it is in line with the recommended validation parameters for QSAR models. The result of the model 1 is given below:

$\mathrm{PIC}_{50}=-0.329720059 * \mathbf{n B o n d s S 3}-0.999544315 * \mathbf{S C H}-7+$ $0.753890542 *$ Pubchem185 $-0.119244628 *$ Pubchem385 + 4.258196 on Hp G630 computer system, with Intel ${ }^{\circledR}$ core $^{\mathrm{TM}}$ i3 Dual CPU, M330@2.13 GHz 2.13GHz, 4GB of RAM using Auto dock vina 4.2 of pyrex virtual screening software, Chimera version 1.10.2 and Discovery studio software. Saccharomyces cerevisiae isomaltase crystallographic structure (Resolution $1.30 \AA$ PDB code $3 \mathrm{AJ} 7$,) with $72.4 \%$ succession identity with the target was used as the mold for this study.

\subsection{Preparation of Ligands and Receptor for Docking}

The 2D structure of the compounds (benzo[d]thiazole) derivatives, were sketch using ChemDraw Ultra 12.0 software. Which were later converted to 3D structures for geometry optimization of the compounds, using Spartan'14 software. PaDEL Descriptor version 2.18 (Yap, 2011; Anonymous, 2013). The structure of gastric proton pump inhibitors, with the PDB code 2Zex receptor was downloaded from Protein Databank (PDB). The 3D structure receptor was prepared by discarding water molecules and cofactors using Discovery studio software (Ravinchandran et al., 2011) and save as Pdb.

\subsubsection{Docking using Autodock version 4.0 of Pyrx software}

The docking, of the ligands (benzo[d]thiazole derivatives $)$ and the receptor $\left(\mathrm{H}^{+} / \mathrm{K}^{+}\right.$-ATpase $)$was perform using Autodock version 4.0 of pyrx software (Trott and Olson, 2010). Chimera 1.10.2 software was used to form the complex (ligandreceptor) since the receptor and the ligand separate after carrying out the docking with autodock vina of pyrx. The complexes were visualized to view their interactions using Discovery studio software.

\section{RESULT AND DISCUSSION}

Four QSAR models were developed using material studio software (Genetic Function Algorithm). And out of these four models, model 1 was selected as the preferable model for predicting the $\mathrm{pIC}_{50}$ for anti-ulcer compounds,

$\mathrm{R}_{\text {trng }}^{2}=0.940021, \mathrm{R}_{\text {adj }}^{2}=0.925026, \mathrm{Q}_{\text {LOO }}^{2}=0.884292, \mathrm{~N}_{\text {trng }}=21$

$\mathrm{R}_{\text {test }}^{2}=0.797578, \mathrm{~N}_{\text {test }}=9$. 
Table 3-Show's the list of the descriptors, their description, and classes for model 1 .

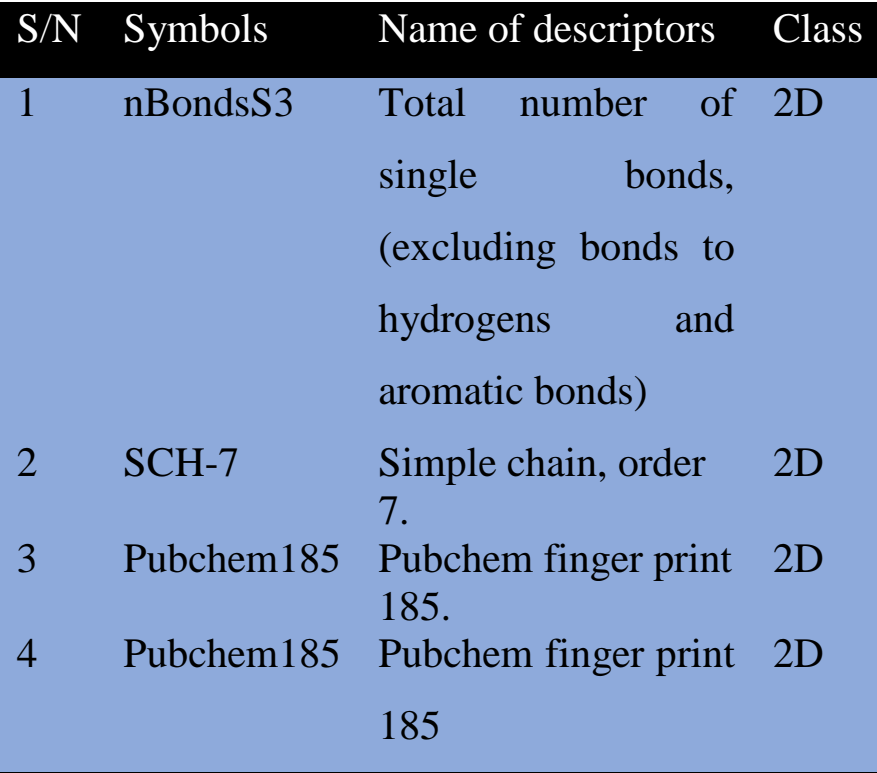

The high $\mathrm{Q}^{2}$ LOO cross verification coefficient calculated $(0.8842)$, for $\mathrm{pIC}_{50}$ shows a valid internal validation of the model, the test set containing $30 \%$ of the biological data set were used for the external verification of the model. The result was found to be 0.7975 which is better than the standard $\mathrm{c} R^{2} p$ parameter value 0.50 for the model.

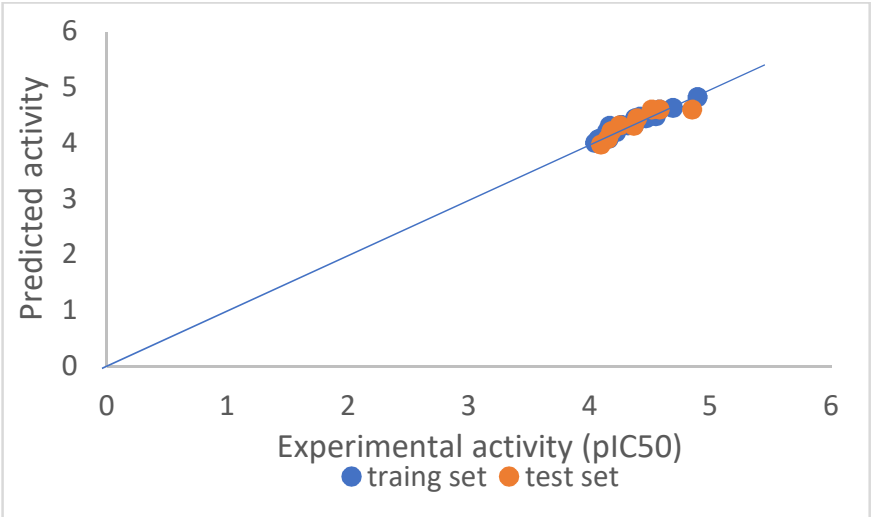

Figure 1 - The plot of the Experimental and predictive activity of both training and test set of the best model (1).

From the above plot of the developed model, we can say that the model is stable and robust, and this is because of the high linearity of the plot (straight line graph). More also the errors propagated on both side of the zero indicate the strength of the model, the prediction of the test set data was determined using the developed model equation. The plot of predicted values comprising both training set compounds and test sets against the experimental $\mathrm{pIC}_{50}$ values are shown in Figure 1. The studied predicted activity is in accordance with the experimental activity. Figure 2 illustrates the plot of standardized residual values versus leverages values $\left(\mathrm{pIC}_{50}\right)$.

A correlation matrix was performed on the descriptors of model 1 , and found to be highly correlated which means tha the descriptors used to build the model are very good. The result of the correlation matrix is shown in table 5 .

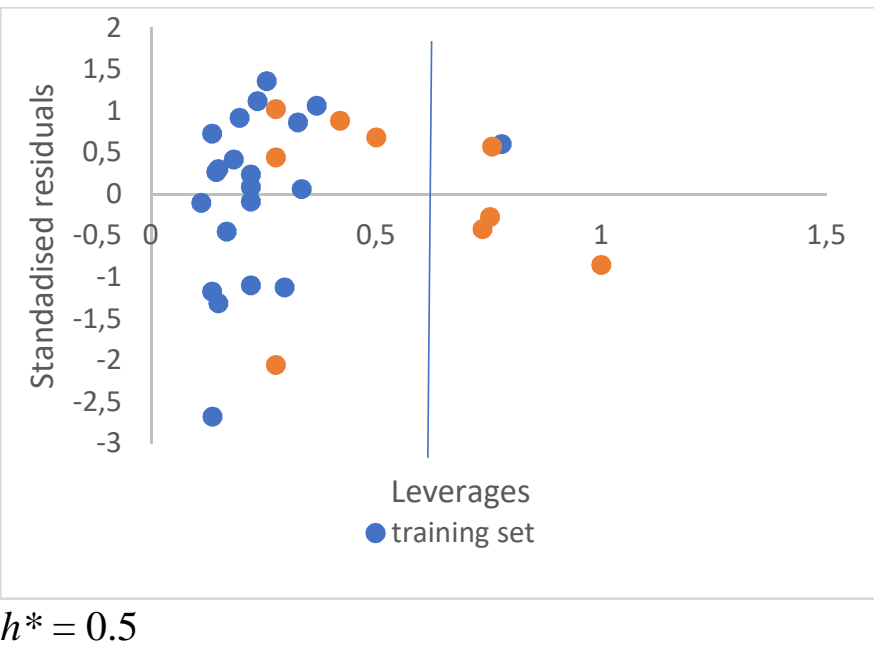

Figure 2- The plot of the standardized residuals versus the leverage value of both the training set and test set of model 1.

From the above plot, it can be deduced that four compounds were found outside the applicability domain, which includes three training set compounds with pIC50 of 4.05, 4.89, 4.69 and one test set compound with $\mathrm{pIC}_{50} 4.39$. The plot also shows that compounds found outside the threshold value $h^{*}$, have very few of the chemical descriptors, and are structurally different when compared to other compounds within the complete data set, i.e. these compounds which could be related to those in the model.

\subsection{Interpretation of descriptors in model 1}

NbondsS3 and SCH-7 have defined as 2D Total number of single bonds (excluding bonds to hydrogens and aromatic bonds) descriptor and Simple chain, order 7, Pubchem finger print 185 and Pubchem finger print 185 It has been clearly shown that an increase in the molecular descriptor nBondsS3 and SCH-7 with decrease in the molecular descriptor Pubchem185 and Pubchem385 will actually increase the antiulcer activity of (benzo[d]thiazole derivatives) against $\mathrm{H}^{+}$$/ \mathrm{K}^{+} \mathrm{ATPase}$ enzymes. The high the binding score of the ligandreceptor complex formed, the better the drug inhibits the target enzyme $\left(\mathrm{H}^{+}-/ \mathrm{K}^{+}\right.$ATPase $)$, thus explaining that benzo[d]thiazole derivatives are very good inhibitors.

\subsection{Molecular docking studies}

Molecular docking studies between the target protein $\left(\mathrm{H}^{+} / \mathrm{K}^{+}\right.$-ATPase enzyme $)$and the benzo[d]thiazole derivatives (ligands) were performed. The result show's that most of the molecules were found to potently block the efficient sites in the target protein $\left(\mathrm{H}^{+} / \mathrm{K}^{+}\right.$-ATPase enzyme). Futhermore, almost the blockers/inhibitors showed high docking scores greater than the ones made by other researchers. For target protein, the binding energy values range from -6.2 to $-9.1 \mathrm{kcal} / \mathrm{mol}$. Compound 22 is the most potent with the high docked score of $-9.1 \mathrm{kcal} / \mathrm{mol}$. Compound 21, and 30 also showed a better docking score of $8.8 \mathrm{kcal} / \mathrm{mol}$ and $-8.5 \mathrm{kcal} / \mathrm{mol}$. Other compounds of the series have average docking scores as shown in table 6 above, while ligands with the best binding energy values are shown in table 7. 
Table 5 - Pearson's correlation matrix for the selected

\begin{tabular}{lrrrr}
\hline & NBondsS3 & SCH-7 & PubchemFP185 & PubchemFP382 \\
NBondsS3 & 1 & & & \\
SCH-7 & -0.19603 & 1 & 1 & \\
PubchemFP185 & -0.50753 & 0.888975 & 0.316228 & 1 \\
PubchemFP382 & 0.562168 & 0.50792 & & \\
\hline
\end{tabular}

Table 6 - Show's the binding energy value, hydrophobic interaction and hydrogen bond interaction formed between ligands with the active site of the $\mathrm{H}^{+} / \mathrm{K}^{+}$-ATPase receptor.

\begin{tabular}{|c|c|c|c|c|}
\hline $\begin{array}{c}\text { Ligan } \\
\text { ds }\end{array}$ & $\begin{array}{c}\text { Binding } \\
\text { energy } \\
\text { (Kcal/m } \\
\text { ol) }\end{array}$ & $\begin{array}{c}\text { Residua } \\
1 \\
\text { interacti } \\
\text { on }\end{array}$ & $\begin{array}{c}\text { Hydrog } \\
\text { en } \\
\text { bond }\end{array}$ & $\begin{array}{c}\text { Hydrog } \\
\text { en } \\
\text { bond } \\
\text { distanc } \\
\text { e. }\end{array}$ \\
\hline \multirow[t]{8}{*}{4} & \multirow[t]{8}{*}{-8.0} & CLR30 & & 4.2778 \\
\hline & & 0 & & 4 \\
\hline & & CLR30 & & 5.4947 \\
\hline & & 0 & & 2 \\
\hline & & EU791, & & 3.8696 \\
\hline & & CLR30 & & 4 \\
\hline & & 01 & & 5.2792 \\
\hline & & & & 5 \\
\hline \multirow[t]{5}{*}{5} & \multirow[t]{5}{*}{-8.0} & CLR30 & & 3.7924 \\
\hline & & & & \\
\hline & & ILE36 & & 5.1596 \\
\hline & & CLR30 & & 9 \\
\hline & & 01 & & 4.3678 \\
\hline
\end{tabular}

\begin{tabular}{|c|c|c|c|c|}
\hline & & LEU79 & & 5 \\
\hline & & 1 & & 5.4203 \\
\hline & & and & & 6 \\
\hline & & CLR30 & & 4.8409 \\
\hline & & 01 & & \\
\hline 11 & 8.0 & CLR30 & & 4.2778 \\
\hline & & 01 & & 4 \\
\hline & & ILE36, & & 5.4947 \\
\hline & & CLR30 & & 2 \\
\hline & & 01 & & 3.8696 \\
\hline & & LEU79 & & 4 \\
\hline & & 1 & & \\
\hline 29 & -6.2 & GLN22 & ASP22 & 2.0628 \\
\hline & & 5 & 8 & 8 \\
\hline & & GLN23 & THR26 & 2.9965 \\
\hline & & 2 & 1 & 4 \\
\hline & & ASP228 & LYS22 & 2.8113 \\
\hline & & & 1 and & 4 and \\
\hline & & GLN22 & GLN22 & 2.7984 \\
\hline & & 5, and & 9 & 2 \\
\hline & & LEU26 & & \\
\hline & & 2 & & \\
\hline
\end{tabular}

Table 7 - Binding Affinity, Hydrogen bond interaction and hydrophobic interaction formed between ligands with best binding energy and the active site of the $\mathrm{H}^{+} / \mathrm{K}^{+}$-ATPase receptor.

\begin{tabular}{|c|c|c|c|c|}
\hline Ligands & $\begin{array}{c}\text { Binding energy } \\
(\mathrm{Kcal} / \mathrm{mol})\end{array}$ & Residual interaction & Hydrogen bond & $\begin{array}{l}\text { Hydrogen bond } \\
\text { distance. }\end{array}$ \\
\hline \multirow[t]{6}{*}{8} & \multirow[t]{6}{*}{-8.1} & TRP931, TRP931 & \multirow[t]{6}{*}{ SER995, PHE999 } & $4.53035,4.78732$ \\
\hline & & TRP988, TRP988 - & & $3.72203,3.97043$ \\
\hline & & ALA966, VAL26 & & $3.86645,4.0203$ \\
\hline & & LEU30, VAL26 & & $5.46087,5.2563$ \\
\hline & & TRP931, TYR970 & & $4.49187,4.91557$ \\
\hline & & TRP988 and & & 4.456 and 4.32655 \\
\hline \multirow[t]{2}{*}{9} & \multirow[t]{2}{*}{-8.1} & CLR3001, CLR3001, & \multirow[t]{2}{*}{ Nil } & $4.27784,5.49472$ \\
\hline & & LEU791 & & $3.86964,5.27925$ \\
\hline \multirow[t]{4}{*}{10} & \multirow[t]{4}{*}{-8.2} & LEU958, LEU958 & \multirow[t]{4}{*}{ SER995, PHE999 } & $2.21234,2.10648$ \\
\hline & & PHE999, TRP931 & & $3.81069,3.97628$ \\
\hline & & TRP931, PHE959 & & $4.05393,4.90821$ \\
\hline & & TRP931, ILE955 & & $5.21098,5.10304$ \\
\hline
\end{tabular}




\begin{tabular}{|c|c|c|c|c|}
\hline \multirow{3}{*}{21} & \multirow{3}{*}{-8.8} & \multicolumn{2}{|l|}{ LEU958, ILE935 and } & \multirow{3}{*}{$\begin{array}{l}4.9788,5.15371 \\
4.86989,5.40695 \\
\text { and } 4.45631\end{array}$} \\
\hline & & & & \\
\hline & & TRP988 TRP988 & ASP128 & \\
\hline & & TRP988, TRP931 & & $3.99059,4.74562$ \\
\hline & & TRP931, PHE959, & & $3.77045,5.13493$ \\
\hline & & TRP931, LEU958, & & $4.87039,5.0393$ \\
\hline & & PHE959, PRO985 & & $4.65917,4.38884$ \\
\hline & & ALA966, VAL26, and & & $5.11076,4.55729$ \\
\hline & & TRP988 & & 4.16245 and \\
\hline & & & & 4.27665 \\
\hline 22 & -9.1 & VAL135, ILE322, & ASP128, ARG979 & $4.45696,3.51146$ \\
\hline & & LEU800, VAL805 & & $2.37976,2.16554$ \\
\hline & & TYR131, LEU978 & & $3.55938,3.77113$ \\
\hline & & LEU132, LEU132 & & $3.80523,3.71011$ \\
\hline & & VAL135 and VAL805 & & $5.52512,5.4223$ \\
\hline & & & & $5.45378,5.2407$ \\
\hline & & & & 4.81062, and \\
\hline 30 & -8.5 & TRP988, TRP988 & Nil & $5.68111,3.86378$ \\
\hline & & TRP988, TRP931 & & $3.89773,4.29311$ \\
\hline & & TRP931, TRP988 & & $4.7893,4.456$ \\
\hline & & ALA966, VAL26 & & $4.88395,3.73009$ \\
\hline & & VAL26, LEU30 & & $3.8604,4.00719$ \\
\hline & & TYR970, TRP988 and & & $5.47397,5.39482$ \\
\hline & & TRP988 & & $\begin{array}{l}4.77903,4.52037 \\
\text { and } 4.42856\end{array}$ \\
\hline
\end{tabular}

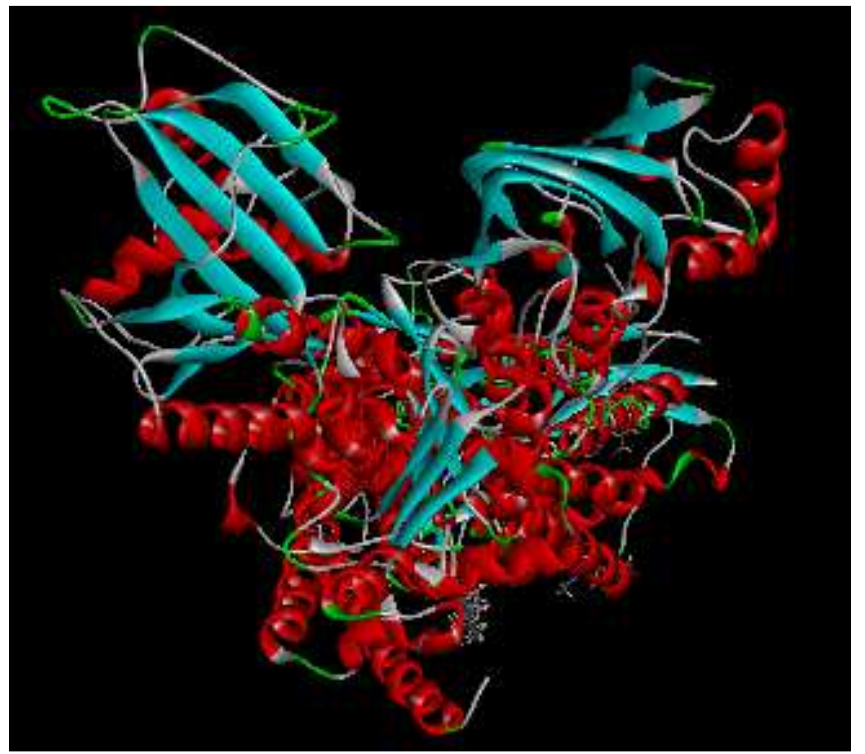

Figure 1 - (a) Prepared Structure of $\left(\mathrm{H}^{+} / \mathrm{K}^{+}\right.$-ATPase $)$.

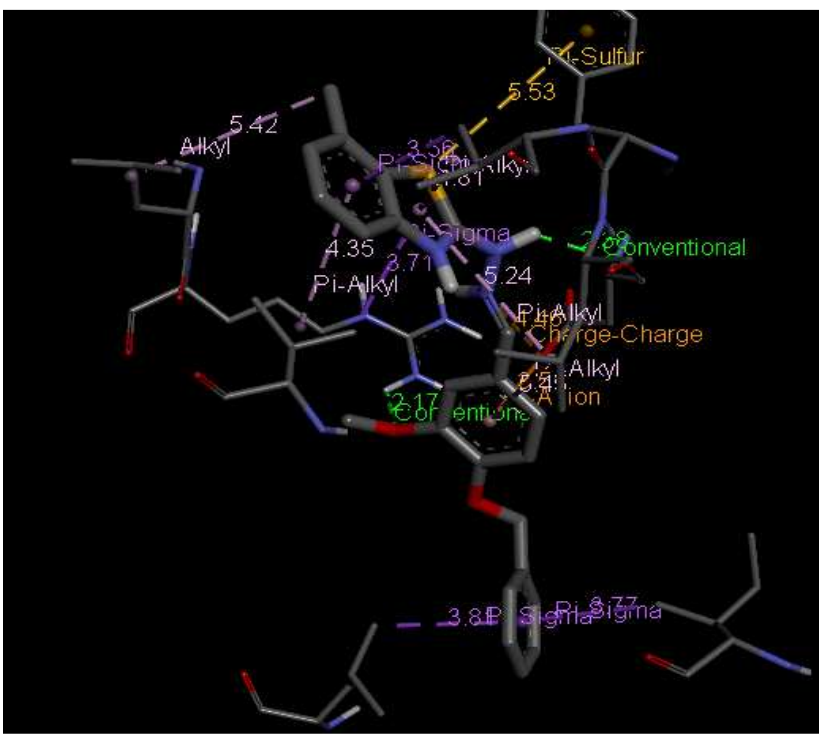

(b) Prepared structure of ligand (benzo[d]thiazole derivatives). 


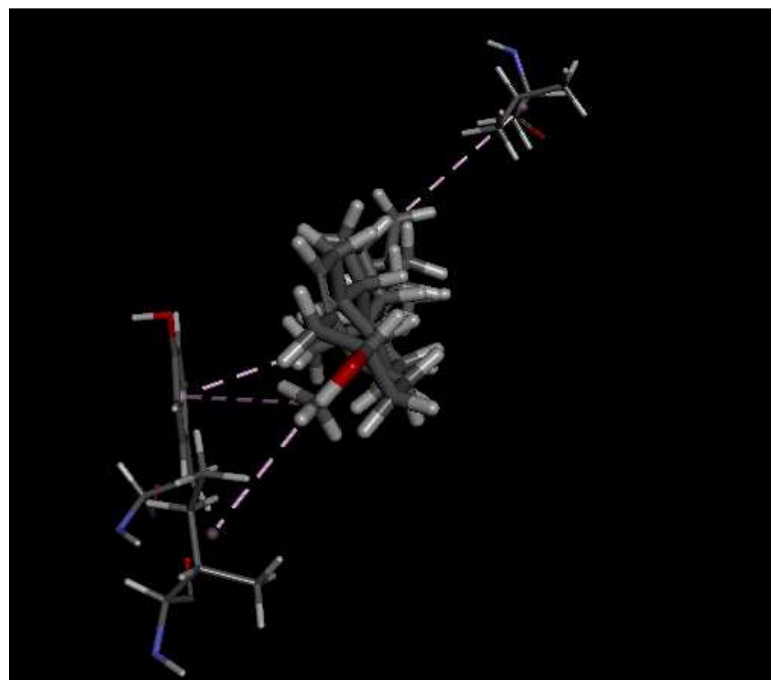

Figure 2 - 2D and 3D structure of Ligand-

Receptor complex $22(-9.1 \mathrm{kcal} / \mathrm{mol})$

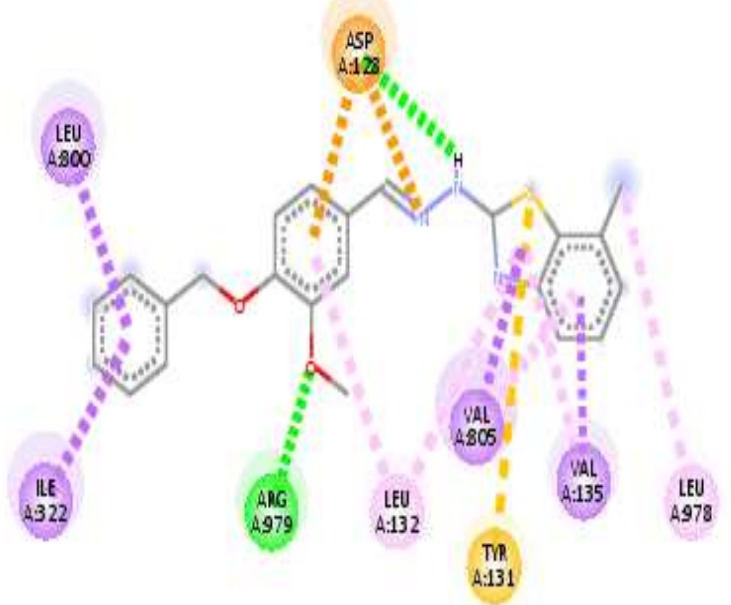

\section{Interactions}

Attractive Charge

Conventional Hydrogen Bond

Pi-Anion

Pi-Sigma

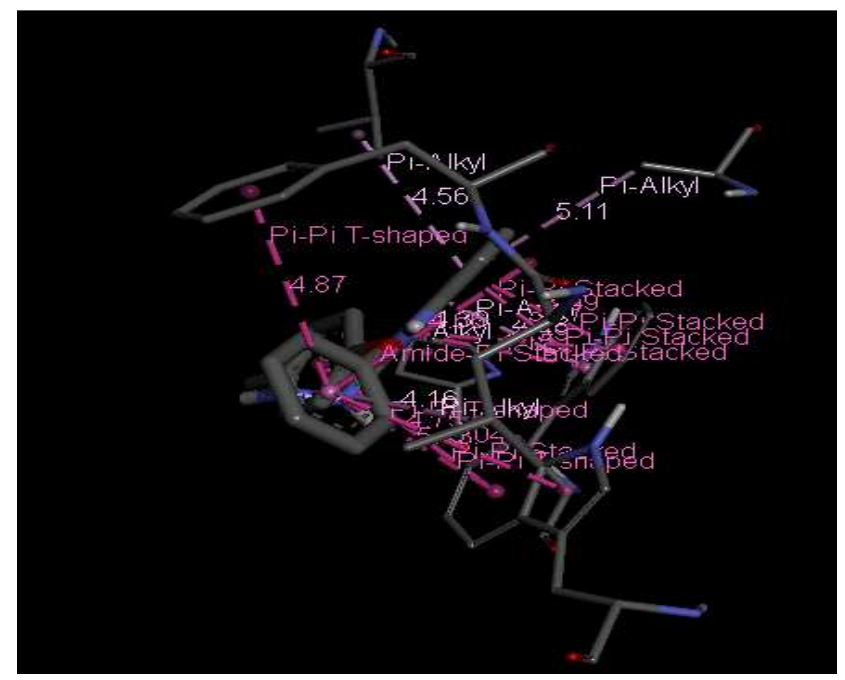

Figure 3 - 2D and 3D structure of Ligand-Receptor complex $21(-8.8 \mathrm{kcal} / \mathrm{mol})$.

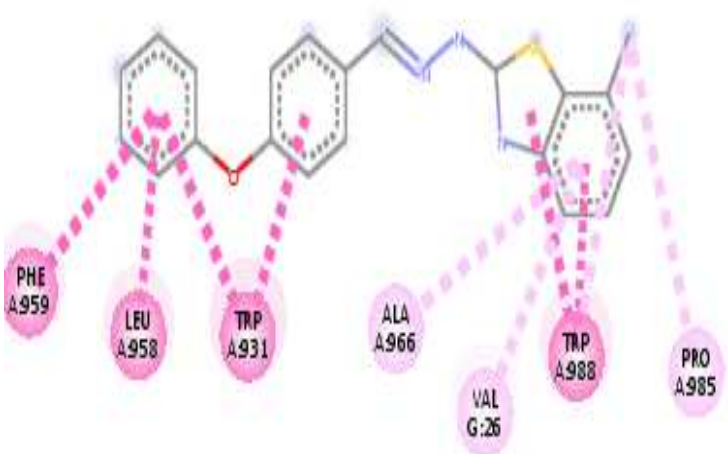

Interactions

Alkyl Pi-Pi Stacked

Pi-Alkyl

Pi-Pi T-shaped

Amide-Pi Stacked 


\subsection{Adherence site of Blockers/inhibitors}

Table 6 and 7 show the least and the best binding scores, hydrogen bond length $\left(\mathrm{A}^{0}\right)$, hydrophobic interactio, and the reactive sediment entangled in the configuration of docking inhibitors at the feasible side of $\mathrm{H}^{+} / \mathrm{K}^{+}$-ATPase. Figure $1 \mathrm{~b}$ and $1 \mathrm{~b}$ is the prepared $\mathrm{H}^{+} / \mathrm{K}^{+}$-ATPase and ligand benzo[d]thiazole structures, compound 22 being the most active molecules form three types of interaction these are Hydrophobic, electrostatic, and hydrogen bond. Benzo[d]thiazole ring was bounded by hydrophobic pockets consisting of amino residues such as VAL135, ILE322, LEU800, VAL805 TYR131, LEU978 LEU132, LEU132 VAL135, VAL805 with two hydrogen bonding of ASP128 $\left(2.379 \mathrm{~A}^{\circ}\right)$ and ARG979 $\left(2.165 \mathrm{~A}^{\circ}\right)$. However, the binding enrgy value generated in thus study was found to be better than the work of (wang et al., 2017), the docked models revealed that $\mathrm{N}-2$ and $\mathrm{C}-16$ of benzo[d]thiazole ring forms a hydrogen bond with amino backbone residue.

\section{CONCLUSION}

It has been clearly shown that an increase in the molecular descriptor nBondsS3 and $\mathrm{SCH}-7$, with the decrease in the molecular descriptor Pubchem185 and Pubchem385 will actually increase the anti-ulcer activity of (benzo[d]thiazole derivatives). Against the $\mathrm{H}^{+}-/ \mathrm{K}^{+}$ATPase enzymes. This is in agreement with the result obtained from the molecular docking analysis in which compound 22a (Fig. 2 and 3) in particular, showed a very good binding affinity of $-9.1 \mathrm{kcal} / \mathrm{mo}$,. along with the hydrophobic pocket interaction of amino residues. The high the binding score of a ligandreceptor complex formed, the better the drug inhibits the target enzyme $\left(\mathrm{H}^{+}-/ \mathrm{K}^{+} \mathrm{ATPase}\right)$, thus explaining that benzo[d]thiazole derivatives are very good inhibitors.

In addition, all the benzo[d]thiazole derivatives docked with $\mathrm{H}^{+} / \mathrm{K}^{+}$-ATPase enzyme were better than even the standard anti-ulcer drug (omeprazole). The physicochemical parameter used for molecular docking and quantitative structure-activity relationship (QSAR) in this study, were essential parameters to look into especially in improving the chance of new anti-ulcer drug as benzo[d]thiazole derivatives. Our QSAR result with high correlation coefficient $\mathrm{R}^{2}$ of 0.7975 and molecular docking result of $-9.1 \mathrm{kcal} / \mathrm{mol}$ correspond with each other and give direction for design of ulcer inhibitors. This study gives room for the synthesis of a new selective $\mathrm{H}^{+} / \mathrm{K}^{+}$-ATPase inhibitor with predetermined affinity and activity of the compound.

\section{Acknowledgments.}

The authors sincerely acknowledge department of chemistry, Ahmadu Bello University, Zaria for its technical support and Dr. Sani Uba and Mr. Usman Abdulfatai for their advice in the course of this research.

\section{R E F E R E N C E S}

Abdulfatai, U.; Uzairu, A.; \& Uba, S. Molecular docking and quantitative structure-activity relationship study of anticonvulsant activity of aminobenzothiazole derivatives. Beni-Suef University Journal of Basic and Applied Sciences (2017).

Arthur, D. E.; Uzairu, A.; Mamza, P.; Abechi, S. E.; \& Shallangwa, G. Insilico Modelling of Quantitative Structure-Activity Relationship of Pgi50 Anticancer Compounds on k-562 Cell Line. Cogent Chemistry, 1432520 (2018).

Anand, K.; \& Wakode, S.; Development of drugs based on Benzimidazole Heterocycle: Recent advancement and insights. IJCS, 5(2), 350-362 (2017).

Anonymous. Wave function. Inc. Spartan' 14 (Version 1.1.2). Irvine, CA. 2013.

Chaudary, S.; Kaila A.; Sharma R. B.; Vashist H.. A review on peptic ulcer, International journal of recent advances in Sciences and technology, 2 6-10 (2015).

DRINI, M.; Peptic ulcer disease and non-steroidal antiinflammatory drugs. Australian prescriber, 40, 91. (2017).

Fashner, J.; \& Gitu, A. C. Diagnosis and Treatment of Peptic Ulcer Disease and H. pylori Infection. American family physician, 91(4) 2015.

Jalali-Heravi, M.; \& Kyani, A. Use of computerassisted methods for the modeling of the retention time of a variety of volatile organic compounds: a PCA-MLR-ANN approach. Journal of chemical information and computer sciences, 44(4), 1328-1335 (2004).

Kaur, D.; Rana, A.; Sharma, N.; \& Kumar, S. Herbal drugs with anti ulcer activity.

Kennard, R. W., \& Stone, L. A.. Computer aided design of experiments. Technometrics, 11(1), 137-148 (2012).

KOUITCHEU MABEKU, L. B.; NANFACK NANA, B.; EYOUM BILLE, B.; TCHUENTEU TCHUENGUEM, R.; \& NGUEPI, E.. AntiHelicobacter pylori and antiulcerogenic activity of Aframomum pruinosum seeds on indomethacin-induced gastric ulcer in rats. Pharmaceutical biology, 55, 929-936 (2017).

Lanas, A., \& Chan, F. K. Peptic ulcer disease. The Lancet, 390(10094), 613-624.

Li, Y.-R., Li, C., Liu, J.-C., Guo, M., Zhang, T.-Y., Sun, L.-P., . . Piao, H.-R. Synthesis and biological evaluation of 1,3-diaryl pyrazole derivatives as potential antibacterial and anti-inflammatory agents. Bioorganic \& medicinal chemistry letters, 25(22), 5052-

Noor, A.; Qazi, N. G.; Nadeem, H.; Khan, A.-u.; Paracha, R. Z.; Ali, F.; \& Saeed, A. Synthesis, 
characterization, anti-ulcer action and molecular docking evaluation of novel benzimidazole-pyrazole hybrids. Chemistry Central Journal, 11(1), 85 (2017).

Rajesh, R.; Manikandan, A.; Sivakumar, A.; Ramasubbu, C.; \& Nagaraju, N. Substituted methoxybenzyl-sulfonyl-1H-benzo [d] imidazoles evaluated as effective $\mathrm{H}+/ \mathrm{K}+-$ ATPase inhibitors and anti-ulcer therapeutics. European journal of medicinal chemistry, 139, 454-460 (2017).

Rakesh, K. P.; Darshini, N.; Vidhya, S. L.; \& Mallesha, N. Synthesis and SAR studies of potent $\mathrm{H}+/ \mathrm{K}+-\mathrm{ATPase}$ and anti-inflammatory activities of symmetrical and unsymmetrical urea analogues. Medicinal Chemistry Research, 26(8), 1675-1681 (2017).

Shi, W.-K.; Deng, R.-C.; Wang, P.-F.; Yue, Q.-Q.; Liu, Q.; Ding, K.-L.; . . . Deng, M. 3Arylpropionylhydroxamic acid derivatives as Helicobacter pylori urease inhibitors: Synthesis, molecular docking and biological evaluation. Bioorganic \& medicinal chemistry, 24(19), 4519-4527 (2016).

Skoglund, A.; Mechanisms of genetic adaptation in Helicobacter pylori: Institutionen för mikrobiologi, tumör-och cellbiologi/Department of Microbiology, Tumor and Cell Biology (2008).

Shamsuddeen, U.; Yusha'u, M.; \& Adamu, I.. Helicobacter pylori: the causative agent of peptic ulcer. Bayero Journal of Pure and Applied Sciences, 2(2), 79-83 (2009).

Tropsha, A.; Gramatica, P.; \& Gombar, V. K. The importance of being earnest: validation is the absolute essential for successful application and interpretation of QSPR models. Molecular Informatics, 22(1), 69-77 (2003).

TROTT, O.; \& OLSON, A. J. AutoDock Vina: improving the speed and accuracy of docking with a new scoring function, efficient optimization, and multithreading. Journal of computational chemistry, 31, 455-461 (2011)

UTZERI, E.; \& USAI, P.. Role of non-steroidal antiinflammatory drugs on intestinal permeability and nonalcoholic fatty liver disease. World journal of gastroenterology, 23, 3954 (2017).

Veerasamy, R.; Rajak, H.; Jain, A.; Sivadasan, S.; Varghese, C. P.; \& Agrawal, R. K.. Validation of QSAR models-strategies and importance. International Journal of Drug Design \& Discovery, 3, 511-519 (2011).

Wang, S.-M.; Zha, G.-F.; Rakesh, K.; Darshini, N., Shubhavathi, T.; Vivek, H.; Qin, H.-L.. Synthesis of benzo [d] thiazole-hydrazone analogues: molecular docking and SAR studies of potential $\mathrm{H}+/ \mathrm{K}+$ ATPase inhibitors and antiinflammatory agents. MedChemComm, 8(6), 1173-1189 (2017).

YAP, C. W.. PaDEL-descriptor: An open source software to calculate molecular descriptors and fingerprints. Journal of computational chemistry, 32, 1466-1474 (2011). 